\title{
An Ebola-Like Microbe and The Limits of Kind-Based Goodness
}

\author{
Berman Chan \\ <berman@lzu.edu.cn> \\ This is the pre-refereed version. \\ Please cite the published (post-refereed) version. \\ Philosophia 50(2):451-471. 2022. \\ https://doi.org/10.1007/s11406-021-00392-w
}

Aristotelian theory, as found in Michael Thompson and Philippa Foot, claims that to be good is to be good as a member of that kind, and so there are varying standards of goodness dependent on an individual's kindmembership. It is a perhaps little noticed feature of Foot's project, in particular, that it aims to provide more than just a kind-relative account, but seeks an exhaustive account of goodness. She concludes, in effect, that goodness admits of only the kind-based sort. Accordingly, an individual's goodness obtains solely in virtue of its satisfying kind-based standards. However, Mark Murphy has argued that a hypothetical "ignorant being" could satisfy its kind-relative standards by being ignorant, but we plausibly judge it to be bad when it does. Thus, an individual's goodness does not obtain solely in virtue of meeting kind-based standards. In this sense, the ignorant being is a counterexample to any Aristotelian account similar to Foot's. Unfortunately, Murphy's counterexample fails because kind-based standards cannot require the lack of something. Nonetheless, I develop Murphy's insight that something can satisfy kind-relative standards but nonetheless be bad-I propose a hypothetical Ebola-like microbe that meets its kind-standards of being destructive for its own sake, but it would plausibly be bad for doing so. In defending my counterexample, I challenge the Aristotelian contention that evaluations should only be made from "within" the standpoint of a particular lifeform conception, rather than an "external" one from which that kind itself can be judged to be bad.

Key words:

Philippa Foot Michael Thompson natural goodness Aristotelian categoricals Mark Murphy goodness excellence good in a kind Micah Lott 


\section{An Ebola-like microbe and the limits of kind-based goodness}

What is it for something to be good? Aristotelian theory contends that to be good is to be good as a member of one's kind, and so there are varying standards of goodness depending on whether something is a squirrel, human, or whatever kind. Appearing in several contemporary versions, ${ }^{1}$ the theory has the advantage of easily explaining, for instance, why having deep, broad roots is a measure of excellence for the oak tree but not for the squirrel, which has a different standard of goodness.

Michael Thompson's and Philippa Foot's version of the Aristotelian account offers to give content to the kind-based standards, using the very conception of the kind of lifeform that an individual organism bears. It is a perhaps little noticed feature of Foot's project, in particular, that it aims to provide more than just a kind-relative account, but seeks an exhaustive account of something's goodness. She concludes, in effect, that something's goodness admits of only the kindbased sort. What follows, with respect to being a good individual, is that a good individual just is good of a kind (is a good oak, good squirrel, etc.) Accordingly, an individual's goodness obtains solely in virtue of its satisfying kind-based standards. However, her account faces an important challenge: there are some things (call these d's) that can satisfy their kind-relative standards, but we plausibly judge them to be bad when they do. Thus, a thing's goodness does not appear to obtain solely in virtue of meeting kind-based standards, and so a thing's goodness is not captured merely by Foot's account. In this sense, such things (d's) are counterexamples to Foot's neo-Aristotelian account. The focus of my discussion will be Foot's account and any Aristotelian theory similar to hers that implicitly offers an exhaustive account of something's goodness. As I later explain, I suspect that many neo-Aristotelian theories would be similar to Foot's in this respect, otherwise they would leave the door open also to an account of a co-existent, kind-independent sort of something's goodness. So, although there may be Aristotelian theories not similar to Foot's in this regard, I will henceforth use 'the Aristotelian account' to refer to all Aristotelian theories offering an exhaustive account of goodness, and will take Foot's account as an important representative.

The aforementioned counterexample-based challenge to the Aristotelian account has been articulated by Mark Murphy. He accepts that the goodness of a thing belonging to a kind obtains partly in virtue of its meeting kind-relative standards. However, in a little thought experiment, he imagines a being for which being ignorant would satisfy its kind-based standard. On the Aristotelian account, if that being were ignorant, that ignorance would be good. Murphy points out, however, that being ignorant cannot be a good feature and so argues that a thing's goodness does not hold solely in virtue of satisfying kind-relative standards. Unfortunately, Murphy's counterexample fails because (for an Aristotelian) the content of the kind-based standard cannot require the lack of something, in this case knowledge. Nonetheless, I develop Murphy's valuable insight that something can satisfy its kind-relative standards but yet not be good when it does, by offering a different sort of counterexample to Aristotelianism, namely an Ebola-like microbe. A member of this kind of lifeform, by hypothesis, would meet its kind-standards by being destructive for its own sake. So, there is a thing which can satisfy its kind-relative standard but is bad when it does, demonstrating that contrary to the Aristotelian account, being good is not only in virtue of satisfying kind-based standards.

In the next section, I briefly present Thompson's and Foot's neo-Aristotelian account. I then discuss Murphy's counterexample to the Aristotelian account, before offering my own

\footnotetext{
${ }^{1}$ See MacIntyre (1999), McDowell (1995), Hursthouse (1999), Thompson (2008), and Foot (2003).
} 


\section{An Ebola-like microbe and the limits of kind-based goodness}

counterexample and argument against that account. I end by responding to the objection, raised by Micah Lott, that to judge a functioning thing to be bad is to take a vantage point external to its lifeform conception ---- a standpoint from which that kind itself can be bad or could be improved. But, so the objection goes, it is mistaken for my argument to take this kind-independent, external standpoint, and so my argument fails.

\section{Thompson's and Foot's Neo-Aristotelian account}

Foot calls the account "the theory of natural normativity", and an account of "natural goodness", 2 but I will call it 'the Aristotelian categoricals account' in order to highlight the account's distinctive theoretical device. Central to the account is what Thompson calls "the representation of life". For any creature that we could represent as living, there is a corresponding "interpretation or understanding of the life-form shared by the members of that class" (Thompson 1995, 288). All of a particular creature's activities, be they hunting, sleeping, or reproducing, are to be recognized as hunting or sleeping only by using that understanding of a lifeform, and representing that individual creature as a bearer of that form. Such an interpretation and understanding of the species is articulated as a set of statements which express the characteristic activities and features of this species. So, for instance, the tiger has four legs, and the wolf hunts in packs are stock examples of Aristotelian categoricals. The categoricals do not necessarily express the statistical facts of the population. So, for instance, even if someone were to surgically remove one leg from every single tiger in the world, it does not follow that the categorical thereby becomes false. Further, because there are numerous Aristotelian categoricals specifying the lifeform, likely no individual creature will perfectly instantiate all the categoricals specified for members of its kind.

Aristotelian categoricals are also teleological, in the sense that they do not merely articulate generalizations about members of a kind having certain features or doing certain activities, but pick out features and activities that relate to the proper ends of the relevant kind. So, the expression of those activities or features

possess certain further possibilities of combination -- in particular, of 'teleological' combination with others of their same form. Their linguistic expressions, that is, are fit to enter into certain sorts of 'final cause'. 'They have blossoms of such-and-such type in order that such-and-such insects should be attracted and spread their pollen about.' (Thompson 1995: 292-293)

Since the features and activities expressed in the categoricals relate to the "final cause" of the relevant species, the categoricals can be the basis on which normative evaluations are made. Foot writes:

[W] hat distinguishes an Aristotelian categorical from a mere statistical proposition [...] is the fact that it relates to the teleology of the species. [...] This is why the noise made by the rustling of leaves is irrelevant in this context while the development of roots is not. And this is why Aristotelian categoricals are able to describe norms rather than statistical normalities. (Foot 2001: 33)

That is, which generalizations count as Aristotelian categoricals depends upon whether those generalizations relate to the teleology of the species, which Foot identifies as species-characteristic ways of seeking: self-maintenance and reproduction (2001: 31), and in the case of humans, reasonfollowing (2004: 11-12). This is why the categoricals form the basis for kind-specific norms of goodness. Each species has its distinct way of seeking its species-teleology, and so each kind has its

\footnotetext{
${ }^{2}$ See, for example, Foot (2001: 49), and the title of that book, respectively.
} 


\section{An Ebola-like microbe and the limits of kind-based goodness}

own set of categoricals, giving rise to different norms of goodness varying with kind-membership. Let me illustrate with a few examples. Blood circulation by heart-pumping is needed for a good human even though it is not required for a good jellyfish, since it does not have blood. The wolf hunts in a pack to obtain food, and so a wolf requires a certain set of social instincts in order for it to be good. By contrast, hunting in a pack is not how the tiger hunts prey. Thus, having the social instincts needed to hunt together is not needed to be a good tiger, which is solitary. The categoricals can also be the basis on which negative normative evaluations are made. An individual which does not satisfy a particular categorical would have a defect. So, a tiger with only three legs would be one suffering from a defect. Similarly, Foot suggests, a human who is unable to recognize and respond to reasons for action would not be a good human (2004: 11-12).

The features articulated in Aristotelian categoricals, then, are the properties that are appropriate for members of the relevant kind. Let us turn now to the question of whether the account contends that a member's goodness is fully explained by its possession of the features identified in the categoricals. Put otherwise, we ask whether the account claims a member's goodness obtains solely (and not merely partly) in virtue of possessing the features identified by the categoricals. To answer this question, we must first clarify what the solely and partly in-virtue-of relations are. Fact $\mathrm{x}$ holds solely in virtue of fact $\mathrm{y}$ just in case y's obtaining by itself determines, and thus fully explains, x's obtaining. A fact $x$ can obtain partly in virtue of fact $y$. Fact $x$ is only partly in virtue of fact $y$ just in case y's obtaining together with that of some other fact(s) determines x's obtaining, and so y only partly explains $x .{ }^{3}$ We can now answer the question posed earlier. The features articulated in Aristotelian categoricals are the properties that are appropriate for members of that kind. Foot contends that the goodness of a member is solely in virtue of the joint possession of those properties. ${ }^{4}$ This latter point that an individual's goodness is solely in virtue of possessing these properties is rather implicit in most of Thompson's and Foot's writings. It becomes more explicit where Foot writes of norms (kind-based standards of goodness) being derived from Aristotelian categoricals. She goes on: "By the application of these norms to an individual member of the relevant species it (this individual) was judged to be as it should be or, by contrast, to a lesser or greater degree defective in a certain respect" (Foot 2001: 34) So, Foot can here be plausibly interpreted stating that satisfying the categoricals is sufficient for an individual to be "as it should be", and thus to be good. ${ }^{5}$ Since satisfying the categoricals (by itself) determines the member's goodness, its goodness is solely in virtue of satisfying the categoricals.

Does Foot take herself to be providing an exhaustive account of goodness? In a well-known essay entitled "Utilitarianism and the Virtues", Foot provides a glimpse into how she conceives of her project of accounting for moral goodness, and thereby also how she conceives of her broader (Aristotelian categoricals) project of natural goodness, moral goodness being a special case of the

\footnotetext{
${ }^{3}$ For instance, something's being a red car is partly in virtue of that thing's being red. The former is also partly in virtue of the thing's being a car.

${ }^{4}$ Since it is plausible for goodness to admit of degrees, the more of these properties something possesses the better it is. Conversely, the failure of something to possess any given (Aristotelian categorical) property would be a defect to some degree.

${ }^{5}$ As failing to satisfy any of the categoricals is a defect, I think it plausible that the goodness of a member is necessarily solely in virtue of the joint possession of the (Aristotelian categorical) properties. In no metaphysically possible world does a member that fails to possess such properties avoid defect.
} 


\section{An Ebola-like microbe and the limits of kind-based goodness}

latter. ${ }^{6}$ In that essay, Foot begins her argument by following Peter Geach (1956) in claiming that there are some uses of the word 'good' such as "'a good event' that do not at least as they stand have a sense. Following this line one might suggest that philosophers are a bit hasty in using expressions such as 'a better world'." (Foot 1985: 199) Foot understands a phrase such as 'a good event' or 'a good state of affairs', by itself, to lack a determinate sense because no particular meaning is provided. Such phrases are also not remedied simply by tacking on 'from a moral point of view' at the end, as simply adding other qualifiers such as 'from a legal point of view' or 'from the point of view of etiquette' does not result in a phrase with a determinate meaning, and it is not clear what makes 'from a moral point of view' any different. Thus, 'good state of affairs from a moral point of view' remains a mere "concatenation of words which in fact has no meaning" (203). However, she recognizes that John Harsanyi and also R.M. Hare provide utilitarian theories "in which a certain interpretation is implicitly provided for such expressions" (203). Nevertheless, while talk of good states of affairs for them has a determinate sense, Foot insists that such talk does not have reference "unless the arguments given by Hare and Harsanyi are acceptable [....]" (204), which arguments she rejects.

Foot is clear in her essay that its aim is to counter utilitarianism, which she says "tends to haunt" even its opponents and so should be directly refuted (196). Now whether or not Foot is correct that the arguments of Hare and Harsanyi are not acceptable, and thus utilitarianism has indeed been refuted, is not my focus here. But what one should notice from the essay is that Foot's project is one searching for defensible sorts of goodness. In the end, she allows that in a way there is such a thing as a good state of affairs, but insists that a truly good state of affairs "appears within morality as the end of one of the virtues", rather than standing "outside morality as its foundation and arbiter" (206). In other words, Foot can accept good states of affairs, in a way, but only from within the standpoint of a virtuous (benevolent) human who seeks the good of others. So, such "good states" have "no special meaning in moral contexts other than the one that the virtues give them" (207). This also implies that the virtues each have a determinate sense, which I think is plausible as benevolence, justice, etc., by nature have their corresponding thick ethical concepts. Foot happens to briefly describe the senses of several virtues (205) while arguing against utilitarianism (205-208). ${ }^{7}$ Thus, her view is that the only sort of moral goodness there is, is that found in the virtues, and it is reasonable to presume that her rejection of utilitarianism helps motivate this. ${ }^{8}$

Foot's project, thus, is not simply to articulate and motivate a sort of goodness found in the virtues, leaving room for the possibility of other sorts as well. If this were her project, there would have been no need for her to refute utilitarianism and its posit of good states of affairs, which could co-exist with the goodness of the virtues. Instead, Foot thinks that the latter would be "haunted" by utilitarianism, and this is because utilitarianism offers a different sort of goodness that is normative

\footnotetext{
6 "Life will be at the centre of my discussion, and the fact that a human action or disposition is good of its kind will be taken to be simply a fact about a given feature of a certain kind of living thing." (Foot 2001: 5) Hence, Micah Lott interprets Foot as holding that "moral goodness is a form of natural goodness in human beings" (2012: 354).

7 This argument (perhaps one of the arguments) is roughly that morality needs to be concerned with more than merely increasing happiness since there are more virtues than benevolence, such as justice; for this reason, even a benevolent person would not do "anything and everything" that increases total happiness (206).

${ }^{8}$ Foot does not refute deontology in her essay, but one may presume this is due to deontology usually being a theory of the right rather than the good. She does not discuss platonism, likely since it was (and remains) not a popular position.
} 


\section{An Ebola-like microbe and the limits of kind-based goodness}

upon humans. This should not have bothered Foot's project if all it sought was an account of the goodness of the virtues (that is not founded upon another goodness), without also requiring that it was the only sort of goodness normative for humans. Thus, Foot's project is after an exhaustive account of goodness in this sense. Indeed, Foot takes her project to have found the only defensible sort of goodness there is, and it is kind-relative natural goodness, ${ }^{9}$ of which moral goodness is a special (human) case. Later in the article, I will argue that the example I offer does present a challenge to Foot's neo-Aristotelianism because it points to a plausible judgment of goodness or badness that cannot be explained by her account. In addition, we have reason to expect that this challenge will not be subject to her critique.

We have seen that each lifeform has its own characteristic features and activities, expressed by Aristotelian categoricals, that relate to its species teleology and form the basis for species-specific norms of goodness. Thompson and Foot do not use the following terminology in this way, but let us call the whole set of these characteristic activities of kind $\mathrm{K}$ 'the function of $\mathrm{K}$ ', such that the function includes both the activities and teleological ends. ${ }^{10}$ For instance, the wolf hunts in packs articulates, of the wolf, one of these characteristic activities (which loosely speaking is one its "functions" $"$, and includes both the activity and the implicit teleological end of self-maintenance. Since the Aristotelian categoricals express each and every one of the activities contained in the function of kind $\mathrm{K}$, and the member of K's goodness is solely (and not merely partly) in virtue of satisfying the categoricals, that member's goodness is also held to be solely in virtue of effectively performing the function of the K.

\section{Murphy's counterexample to the Aristotelian account}

Thus the Aristotelian account would claim that for any member of kind K, that member's being good obtains solely in virtue of its performance of the function of $\mathrm{K}$ (to use our function terminology). Now consider for a moment the question: How far can we take the Aristotelian account, and in particular the claim that a member (of K)'s goodness is solely in virtue of effectively performing its function, whatever that function is? Mark Murphy's insight is that it does matter what its function is. He asks us to imagine "a lesser god" who creates a being that is designed to be ignorant, friendless, and unable to appreciate beauty.

A lesser god might fashion a being that ought not to --- that is, it would be defective with respect to its design plan if it came to --- know things, or to make a friend, or to appreciate something beautiful. But we would resist the view that these things are admirable or lovable just by exhibiting the features being dead or being ignorant or being friendless. (Murphy 2011: 160, italics not added.)

\footnotetext{
${ }^{9}$ Foot includes attributive good (goodness as a member of a kind) but also includes "what is good for anyone or anything, or about that in which their good consists" (1985: 202) as aspects of kind-relative goodness which she would later call natural goodness. In my discussion of Foot in this article I focus on the aspect of attributive good.

${ }^{10}$ The reason to introduce this terminology of 'function of K' in addition to the function of a body part of a $\mathrm{K}$ is that we are assessing the Aristotelian theory as an account of the goodness of individual things instead of merely their parts. At any rate, categoricals for the individual things as a whole are not foreign to Foot, given her examples regarding the deer's swiftness for eluding predators and cooperative hunting of the wolf (2001 34). Some motivation for both the priority of the individual's functions, and for functions as activities, can be found in James Lennox's (2017 42-44) reading of Aristotle's focus on the whole organism and its "certain complete actions".

${ }^{11}$ The function of a given $\mathrm{K}$ is a set of several activities, but loosely speaking each of those activities is a function.
} 


\section{An Ebola-like microbe and the limits of kind-based goodness}

For simplicity, let us focus on the feature of ignorance. Being ignorant is intuitively not a good feature even if possessing it fulfills that being's "design plan" and thus also satisfies its kind-based standard. While being ignorant might have some good effects, such as avoiding being targeted as a political threat in a totalitarian government (my example), Murphy's point is that on the Aristotelian account it would follow that the being's ignorance is good for its own sake. ${ }^{12}$ But intuitively, being ignorant is not. Murphy does allow that good can come of ignorance, death, and the like, but argues they are not good for their own sakes. Regarding a thing's death, he writes: "When a thing's dying is admired, it is not admired as such, but as something that is accepted as just necessary, or as for the sake of something better or avoidance of something worse." (159)

If Murphy's example succeeds, then it is a counterexample to the Aristotelian account of what goodness is solely in virtue of. Murphy has quite rightly seized upon the insight that it is not the case that things are good solely in virtue of performing their function. ${ }^{13} \mathrm{I}$ argue, however, that his example does not clearly impugn the Aristotelian account and does not cleanly bring out the insight just mentioned. There is a fundamental problem with Murphy's example. Clearly, being ignorant is a privation (of knowledge). I argue that genuine Aristotelian kinds have functions which are positive features instead of privations. So, some so-called function to not do or not have something does not count as a genuine function. Thus, on Aristotelianism, something having such a "function" will not be a metaphysically possible thing, and thought experiments ought not to use it. The argument for this acceptance of Aristotelian functions as positive features but not privations can be made by bringing out in more detail my earlier claim that function is an activity. Aryeh Kosman's interpretation of Aristotle provides a basis for such an account of function. Kosman's answer to the question of what it is to be something (to be a member of kind K), is to act as Ks act, which is to engage in the characteristic work (ergon -- function) of the K.

To be a horse is to perform the characteristic activities in which a horse engages in leading its equine life, the horse's characteristic work: its ergon. To be a horse is therefore to be at work- energos - as a horse, or in other words - and this is the prize we were after - it is to be actively - energeia — a horse. (Kosman 2013: 122)

To be a horse is to engage in equine activity. Earlier, I characterized the 'function of K' as the set of characteristic activities of kind $\mathrm{K}$, and so 'function of $\mathrm{K}$ ' roughly corresponds to what Kosman calls the characteristic work (ergon) of that kind. Thus, function is a positive sort of "work" rather than an avoidance of some activity. This is what Kosman puts so aptly above, that performing the horse function "is to be actively---energeia --- a horse". So, something's function cannot be to be ignorant, since that does not specify an activity but rather what to avoid (knowledge). For similar reasons, something's function cannot be to be uncultured, and so on. ${ }^{14}$

\footnotetext{
${ }^{12}$ In the terminology of Christine Korsgaard's "Two Distinctions in Goodness" (1983), such goodness would be properly called "final" goodness, as contrasting with instrumental goodness.

${ }^{13}$ Using this insight as a springboard, Murphy's own proposal is that in addition to meeting its kind-based standards, there is a further condition for something's goodness. "So I say that the best theistic account of the good will take what constitutes a thing's goodness to be jointly fixed by Godlikeness and by its kind --- being like God in ways that belong to the kind to be like God." (Murphy 2011, 160)

${ }^{14}$ What, then, of static categoricals such as the tiger has four legs? Unlike the wolf hunts in packs, the former does not express an activity. Perhaps the static trait may be more properly expressed as a particular way by which the lifeform performs its activities, such as the tiger hunts four-leggedly (and the tiger defends itself four-leggedly, etc.)
} 


\section{An Ebola-like microbe and the limits of kind-based goodness}

An effective counterexample to the Aristotelian account

Even though Murphy's counterexample does not get off the ground for the reason above, I accept his insight that some things can meet their kind standards without being good. In the remainder of this article, I will retain that insight but develop it by offering an effective counterexample that avoids the problem plaguing Murphy's example. It is an Ebola-like microbe whose function includes destroying organisms by attacking their early-detection system before devastating their vascular system. This microbe is not the actual Ebola virus, but a microbe similar with respect to method and effectiveness of transmission, as well as similar in power. If the function of the actual Ebola is not to destroy organisms, my proffered counterexample would not be affected; the function of the Ebola-like microbe includes the end of destroying organisms (just for the sake of destruction), and this function is stipulated by hypothesis. Counterexamples to an account of goodness do not have to be actual individuals (or members of actual kinds), but rather metaphysically possible individuals (or members of metaphysically possible kinds). There is another reason that the Ebola-like microbe is not the actual Ebola virus, and the reason is that it is not a virus. Viruses depend directly on other lifeforms for their operations. For instance, while a member of an Aristotelian lifeform takes in nutrients and converts them into the energy it needs, viruses depend on their host to metabolize that energy. Indeed, most of the virus' biological activities are really done by their hosts, but under viral control. This is one reason it is controversial that viruses are lifeforms. To ensure that the Ebola-like thing belongs to a kind of Aristotelian lifeform, I have stipulated that it is not a virus but a different kind of microorganism ('microbe'). ${ }^{15}$ This kind of microbe does not rely on a host's metabolic processes and energy, but carries out its own microbiological activities, including evading detection and destroying an affected organism's vascular system.

Ex hypothesi, the microbe is such that at least one of its functions has the teleological end of destruction for its own sake. In contrast to say, the rabbit which "destroys" the carrots and grasses it eats, the Ebola-like microbe has at least one function whose end is destructive of others for the sake of destruction, while the rabbit destroys for the sake of nutrition. ${ }^{16}$ The Ebola-like microbe is a counterexample to the Aristotelian account because it is bad when it performs its functions. We know by intuition that a functioning Ebola-like microbe is bad --- we know that something is (noninstrumentally) bad which functions to ravage mammals by rapid infection, for the sake of destruction. But on the Aristotelian claim that a thing's goodness is solely in virtue of functionperformance, the microbe would be good; its badness cannot be accounted for by Aristotelians, ${ }^{17}$

\footnotetext{
${ }^{15}$ If an Aristotelian believes that microbes are also merely borderline substances, then let the Ebola-like thing be an insect, like the smallest known insect S. musawasensis beetle (Polilov 2015) which is as small as some single-celled organisms. In this case, the Ebola-like thing's method of transmission (infestation) would be slightly different from actual Ebola's, although its power to destroy and effectiveness of transmission could remain similar to it.

${ }^{16}$ For the same reason, the counterexample I offer should be contrasted with the bottlenose dolphin, whose mating practices (perhaps similar to sexual assault) may be disturbing to the reader. Shane Glackin (2008) points out that male bottlenoses form alliances with other males, usually relatives, to coerce unwilling females into sexual intercourse. However, the sort of counterexample I offer is significantly different from the bottlenose, since it is arguable the latter's coercive copulation is not for the sake of coercion or injury but for the sake of reproduction. 17 One of Foot's defenders, Micah Lott, recognizes that there is some basis to a similar sort of judgment of badness. However, it can nonetheless be accounted for by Foot's theory, particularly from the perspective of the benevolent human (Lott 2012). I show at the end of this article that his response is not successful.
} 


\section{An Ebola-like microbe and the limits of kind-based goodness}

even though the Aristotelian account purports to be an exhaustive account of something's goodness or badness. So, the Ebola-like microbe is a counterexample.

Strictly speaking, the Ebola-like microbe would plausibly have more functions than to destroy organisms (in the way it does), since the microbial lifeform would have other categoricals pertaining to its self-sustenance and other aspects of life. So, strictly speaking, one should not reason from a particular microbe's performance of its destructive function to concluding it is thereby a good Ebola-like microbe as a whole. Instead, we should conclude that the performance of that function is good-making, arguing in the following fashion: If the Aristotelian account is correct that an individual thing's goodness is solely in virtue of performing its function, then performing any of their proper functions is good-making. For some things, performing some of their functions is not good-making. So, it is not the case that the solely-in-virtue-of claim of the Aristotelian account is correct. However, for the remainder of this article, often I will speak of the counterexamples being good (as a whole) by Aristotelian lights in virtue of performing its destructive function, assuming the other functions were being performed as well. But my arguments will all go through even if formulated in the more careful way.

The counterexample I offer is such that its destructive effects are part of (are partly constitutive of) its function. ${ }^{18}$ Unlike the ignorant being, whose positive effects ${ }^{19}$ (if any) would constitute the instrumental goodness of that being, any destructive effects of the Ebola-like microbe would constitute the non-instrumental goodness of the microbe, for the following reason: If a thing's function includes (i.e. is partly constituted by) producing certain effects $(E)$ on others, an Aristotelian should accept that the thing would be non-instrumentally ${ }^{20}$ good for producing those effects (E). For instance, say a human's function includes being generous, which is to give to others. This function includes producing an effect, namely the effect (E') of things being given to others. Further, and this is the point, a human who produces effect E' (in a generous way) would not merely be instrumentally good for producing that effect. Rather, the Aristotelian should say that the human is non-instrumentally good, since that effect is part of its function instead of a further effect of that function. Given this principle, then, and by Aristotelian lights, the Ebola-like microbe is noninstrumentally good in virtue of the destruction it brings to other things. But the microbe performing that function is non-instrumentally bad, we know intuitively. Thus there is a problem for the Aristotelian account.

Now, suppose the destruction wrought by my counterexample (the living thing) were to cause further effects, some of which happened to be good. For instance, imagine that the Ebola-like microbe in one metaphysically possible world brought some small benefit to the ecosystem, such as providing a little carcass-meat for a few scavengers. In such a world, providing a little meat for scavengers would be a further effect of its destructive function. Thus, the microbe would merely be instrumentally good for these positive effects. Such an Ebola-like microbe that destroyed organisms (for destruction's sake), however, would nevertheless be non-instrumentally good by Aristotelian

\footnotetext{
18 The Ebola-like microbe's function is a set of activities, one of them being, say, to secrete toxins so as to destroy an organism's vascular system. The activity here is secreting toxins while the species-teleology is the destructive effect on organisms. In this way, the destructive effect constitutes (i.e. is part of) the function. And the function includes (i.e. is constituted by) that effect.

${ }^{19}$ E.g. avoiding being targeted by a totalitarian government because the being is ignorant.

${ }^{20}$ See footnote 12 about Korsgaard's use of 'final' goodness as the contrast to 'instrumental' goodness.
} 


\section{An Ebola-like microbe and the limits of kind-based goodness}

lights, as it performed its function. But it is non-instrumentally bad, and we know it, regardless of what further positive effects come about.

What determines the content of the function of a given kind? This is not an epistemological question of how one would know what that function is, but instead the metaphysical question of what the function of the $\mathrm{K}$ is, and what determines its content. It is plausible that destruction is not part of the function of actual Ebola, but that it destroys for the sake of self-maintenance or reproduction. In contrast, I claim that destruction for its own sake is part of the function of the Ebola-like microbe. Imagine that the microbe's activities targeting surrounding organisms brings about both nutrition for itself and the destruction of those organisms. Of these outcomes, which are included in the microbe's function, self-maintenance and destruction, or merely self-maintenance? My argument hinges upon destruction also being included. True, the Aristotelian categoricals account does set the content of K's function. That account emphasizes that this content is an implicit representation of the lifeform, that the content is not a statistical claim, and that they should form the basis of normative evaluations. Now, however, the request is to make the representation of the lifeform more explicit, to yield an elaboration of what decides the content of the categoricals, including the species-teleology of the kind in question.

While I have a preference for how the general contours of an account of function should go, ${ }^{21}$ for the purposes here all that is needed is that there be some Aristotelian metaphysical account of what constitutes a K's function. Here we need not take a stand on a particular account as long as there is some account. ${ }^{22} \mathrm{I}$ am addressing Aristotelians, and the vast majority would accept that every kind has some function (or set of characteristic activities for a given kind), according to some account of what decides that function. Equipped with such an account, whatever it is, we would then be able to answer the question in the previous paragraph about what the Ebola-like microbe's function includes. If its function includes destruction, then assuming there is a metaphysically possible world in which it performs that function, we would have a counterexample. If instead the function does not include destruction for its own sake, then this Ebola-like microbe would not be a

${ }^{21}$ My preferred account of what determines the K's function is that it is in virtue of the form of the K. Here I follow the broad strokes of Scott Macdonald's reading of Aquinas. On that reading, every thing is a member of some species S (what I have called kind $\mathrm{K}$ ) in virtue of the thing's "having the capacity for performing the activity characteristic of Ss" (Macdonald 1990, 329). This activity, including the end to which it aims, is what I have called the function of Ks. Macdonald goes on to read Aquinas as contending that such a capacity (constituted by a set of powers and potentialities) for performing S-characteristic activities is in turn in virtue of the substance's substantial form, which "is the ontological ground of that capacity" (329).

22 There is of course a vast literature about function from the philosophy of biology (e.g. Wright, L. [1973], Boorse, C. [1976], or Bigelow and Pargetter [1987]). True, an evolutionary-etiological account will not account for an activity's function to destroy for its own sake, since on that account the function of an activity is the adaptive feature for which the trait was selected. All adaptive features have the end of fitness and reproductive success rather than destruction. Nevertheless, most of these contemporary accounts of biological function are not compatible with Aristotelianism, and any neo-Aristotelian account of biological function will likely need to (re)introduce notions such as form and powers (see Lennox [47-49] for instance) and function will not be restricted to being accounted for merely by the adaptive feature for which a trait was selected. Later I address neo-Aristotelian worries about destruction being a function. 


\section{An Ebola-like microbe and the limits of kind-based goodness}

counterexample. But then the details of the hypothetical example could be modified $^{23}$ so that it does count as a counterexample. In order to successfully object to this move, the objector would be tasked with the difficulty of demonstrating that it is metaphysically impossible for there to be something akin to the Ebola-like microbe which has destructive functions, on any plausible account of functions available to the Aristotelian. I show later below that this objection fails.

At this point it is also worth pointing out that the counterexample argument I offer also challenges other neo-Aristotelian accounts. This is because their accounts of goodness also rest upon the notion of the proper function of a given kind. The notion of function arises in Rosalind Hursthouse's mention of a social animal well-fitted and endowed to serve its teleological ends "in the ways characteristic of the species" (Hursthouse 1999, 202), and Alasdair MacIntyre's appeal to "the distinctive powers that [something] possesses qua member of that species" (MacIntyre 1999, 64). I have offered examples of things that achieve their teleological ends in ways characteristic of their species and species-endowments, or things which activate their distinctive species-powers, yet are bad when they do. If Hursthouse or MacIntyre do not claim (as Foot does) that kind-relative goodness exhausts all the goodness there is, then they would have to concede that there is also a kind-independent standard of goodness. Thus, to the degree these other authors want to reject this concession, to that degree they would assert that a thing's goodness is solely in virtue of functionperformance, and thus the example I offer would also be effective against their neo-Aristotelian accounts.

Lastly, even though it challenges Aristotelian views on goodness, I wish to make clear that my counterexample argument is not a challenge to the view that (for things belonging to a kind) an individual's goodness is partly in virtue of satisfying kind-dependent standards. ${ }^{24}$ Instead, it shows only that satisfying those standards is not what something's goodness is solely in virtue of. Nonetheless, in showing that satisfying kind-based standards is not enough for goodness, my counterexample argument provides reason to be optimistic about an account of goodness which includes a kind-independent standard in some way, the details of which I hope to flesh out in future work. Such further work would not only more precisely delineate the sense of something's goodness, as Foot required (following Geach), but also more fully argue for its having reference.

\section{Objection 1: Is destruction a possible function?}

Let me now address an objection. A defender of Foot might argue that a function whose end is destruction is not a metaphysically possible function. If this is correct, then my counterexample would fail, relying on a "function" whose end is destruction. Earlier, we saw that Foot argues that the categoricals account needs to go further than Thompson does, and that is to specify the content of species-teleology. She states of the categoricals that "in plants and non-human animals these things all have to do, directly or indirectly, with self-maintenance, as by defence and

\footnotetext{
${ }^{23}$ For instance, on an account based on the form of the K (see footnote 21 ), the microbe example would be modified from one having a form whose associated function is to provide carcass meat to a few scavengers, to that whose function is to destroy.

${ }^{24}$ One might, I suppose, support this partly-in-virtue claim by deploying Foot's point that cooperative hunting is required for the wolf, and swiftness for the deer (2001: 34). One could then go on to argue that activities goodmaking for the wolf (e.g. cooperative hunting) are not so for the deer, and so something's goodness is partly in virtue of satisfying its kind-based standards. William Fitzpatrick (2008: 186) and Mark Murphy (2011: 155-9) each offer similar arguments for the partly-in-virtue claim.
} 


\section{An Ebola-like microbe and the limits of kind-based goodness}

the obtaining of nourishment, or with the reproduction of the individual, as by the building of nests." (Foot 2001: 31) The activities expressed by the categoricals must relate to these ends in order "to isolate the kind of proposition that will yield evaluations of individual organisms" (30), propositions having to do with species-teleology. This is how we may reject a would-be categorical about the rustling noise of oak leaves in the wind but accept that of the development of its roots, since only the latter relates to self-maintenance or reproduction. However, with respect to determining which candidates should count as Aristotelian categoricals, I argue it is enough to require that a categorical expresses an activity that does relate to what the species-teleology of that lifeform is, whatever the content of that species-teleology, without setting limits on that content. Now, I do think that the species-teleology for all Aristotelian kinds will include the ends of selfmaintenance and reproduction (especially the former ${ }^{25}$ ). However, for the purpose of including all and only propositions relevant to the species-teleology, it is not needed to go further and limit the content of that teleology to those two ends, again, as long as one requires that all categoricals be aimed at its teleology, whatever it may include in addition to those two ends.

Another reason to disagree that the species-teleology should be thus limited is that in the case of humanity, Foot already opens the door wider regarding species-teleology, as she contends that for humans the categoricals will include those relating to other ends such as recognizing and responding to reasons for action (reason following). ${ }^{26}$ Of course Foot is not guilty of inconsistency, since she was always clear that limiting species-teleology to self-maintenance and reproduction only applied to plants and non-human animals. My point is simply that for the same reason that she opens the door wider when it comes to the human, that reason also widens the door for hypothetical and unknown lifeforms. Foot argues that the species-teleology of the human, the human good, can be articulated by reflecting on the things without which the human would be deprived. The human needs "the mental capacity for learning language; they also need powers of imagination that allow them to understand stories, to join in songs and dances -- and to laugh at jokes. Without such things human beings may survive and reproduce themselves, but they are deprived." (2001: 43) So, due to what we might call the deprivation principle, in addition to maintenance and reproduction, the range of species-teleology for the human is widened to include the human good, which in turn includes ends like reason following.

With the door thus widened, either these sorts of ends exhaust all the metaphysically possible species-teleologies for any kind, or they do not. It is plausible they do not, since there are other plausible candidates such as pleasure and beauty. ${ }^{27}$ That is, for some hypothetical species, activities seeking pleasure and beauty are pursued not merely for the sake of self-maintenance, reproduction, or reason-following. Instead, these hypothetical lifeforms seek to experience pleasure and beauty as ends in themselves, and this seems plausible. Thus, taking into account hypothetical possible lifeforms, the good of a hypothetical (or unknown) lifeform may be such that activities aimed at merely surviving, reproducing, (and even reason following) would nonetheless lead to a

\footnotetext{
${ }^{25}$ Here I have in mind hypothetical kinds of lifeforms which are immortal, and so may not reproduce but whose species-teleology will nevertheless include self-maintenance. But this point is not crucial to my argument.

${ }^{26}$ Foot writes that in the botanical and zoological worlds, once a species' feature or operation has been related to survival and reproduction, "questions of 'How?' and 'Why?' and 'What for?' come to an end. But clearly this is not true when we come to human beings." (Foot 2001: 42). "Natural goodness in reason following is as much a form of goodness in humans as is proper instinctive behavior in animals" (2004: 11-12)

${ }^{27}$ Notwithstanding the view that esthetics is subsumed under reason following (rationality).
} 


\section{An Ebola-like microbe and the limits of kind-based goodness}

deprived life, without pursuing the end of pleasure or some other end. Then, by the deprivation principle, it is plausible that there are more sorts of possible ends in addition to the ones Foot envisions, including the end of destroying other things.

\section{Objection 2: The view from "outside" the lifeform}

The next and final objection that will be discussed complains that the counterexample argument implicitly assumes a particular vantage point from which an evaluation is made---a vantage point external to a lifeform conception. Recall that the counterexample argument claimed, contra the Aristotelian account, that some things which perform their function are not good. The defence of this claim had used the example of an Ebola-like microbe, whose function-performance was noninstrumentally bad, and we knew this intuitively. However, an Aristotelian might reject the very vantage point from which we judge that the microbe is bad, that is, reject a lifeform-external vantage point from which a particular lifeform itself could be judged to be bad. Micah Lott provides perhaps the clearest explanation why a defender of the categoricals account would reject that vantage point, asserting that judgements of goodness are only to be made internally to the life form:

In identifying Aristotelian categoricals, we articulate an understanding of the life form. The corresponding judgments of function and natural goodness are made by representing the individual as a bearer of that form. These judgments depend on an understanding of the relations of dependence within the life form. But judgments of natural goodness nowhere depend on the idea that it is in some further sense good that this is how things stand with respect to this life form. (Lott 2012: 366, italics not added.)

Responding to the view that a benevolent designer would not have male elephant seals fight to the death for their mates, ${ }^{28}$ Lott points out that such a view would arise "only when we consider the lifeform 'from without' and imagine how the lifeform itself might be improved or made 'better' for its bearers.” (Lott 2012: 366) But any lifeform should be evaluated solely from within. Thus, the judgment of badness made from a perspective external to the lifeform, which was a kindindependent vantage point crucial to my argument, is misguided and confused. Foot also gives this sort of response to the case of "pestilential creatures" (2001 49), which she would likely have called my proffered counterexample. The survival of pestilential creatures is not bad nor are their deaths good in any external sense since goodness is only to be judged from within the framework of the Aristotelian categoricals for that kind (pestilential creature).

Now this is not to say that Lott thinks the virtuous human should be indifferent between violent and non-violent mating practices. But what explains the difference between the seemingly better and worse one is not that there is something kind-independently better about one, but rather that our human morality gives us reason to prefer one over the other. So, Aristotelians like Lott do not wish to completely close the door to the reasonableness of making evaluative judgements of the lifeform conceptions themselves. As I mentioned earlier, Lott opens the door to judging that a functioning elephant seal is bad in some sense for its violent mating ritual, but such a judgment is ultimately grounded upon "what a virtuous person aims for -- as an end related to a given virtue, such as benevolence -- but not as something standing prior to morality which it is the business of morality to promote." (Lott 367 fn 31) Then, there may be reason for a virtuous human to

${ }^{28}$ This is an example due to William Fitzpatrick. He argues that a benevolent designer would not design such a practice, and even if the Aristotelian "natural goodness" account says that members of a kind which practices such mating rituals are good, Fitzpatrick would reject the account [2000: 72, 79]. 


\section{An Ebola-like microbe and the limits of kind-based goodness}

rehabilitate the elephant seals, for instance by training them "to find mates via some less aggressive means" (367). This is Lott's way of illustrating Foot's recognition that it does make sense to ask the question of which action will most relieve suffering or promote justice, but that the proper place for such an enquiry is "somewhere within morality" (Foot 2001: 49), which is the vantage point of the virtuous human. As this is the standpoint of the human's lifeform conception, the Aristotelian can accommodate the judgement, in some sense, that a version of the elephant seal which finds mates without maiming or killing competitors is better. Moreover, the Aristotelian would not have to concede that an elephant seal which finds mates in the usual violent manner is bad, that is, "kindindependently" bad from a vantage point external to any lifeform conception. Neither does that concession have to be made about a functioning Ebola-like microbe, and so our judgement about the microbe need not imply that it is "kind-independently" bad. But without this implication, my argument cannot show that the evaluation of the microbe offered by the Aristotelian account is mistaken, as this evaluation would come from the kind-based standpoint of the virtuous human. Thus, my argument would not be offering an effective counterexample to that account.

However, one might press the Aristotelian that some plausible comparative judgements cannot be accommodated by reference to the virtuous human viewpoint. For instance, a functioning Ebola-like microbe that destroys just as much as a functioning (actual) Ebola virus would be equally bad to the virtuous human, given the human's benevolent commitment to reducing animal suffering. However, it is intuitively plausible that the microbe should be judged to be worse than the virus, as the aim of the former's function includes destruction for its own sake. Yet, the appeal to the benevolent human standpoint cannot explain this, and so the functioning microbe is not good or bad solely in virtue of considerations from that standpoint or lifeform conception. Second, the neoAristotelian has not actually given us an argument that only the vantage point internal to a lifeform should be used to evaluate something's goodness. Thus, the neo-Aristotelian owes us an argument that it is mistaken to appeal to a view external to the lifeform, and until then, the counterexample I offer is effective against the Aristotelian account. Let me flesh out this argument below.

First, some plausible judgements of a comparative nature cannot be explained by the virtuous human viewpoint. Consider an actual Ebola virus, which is a member of a kind whose function is to destroy organisms for the sake of its own survival, and an Ebola-like microbe that is a member of a kind whose function is to destroy for destruction's sake. Further suppose that each performs its function effectively, and in doing so carries out exactly the same amount of destruction and causes an equal measure of pain and suffering. Considering either of these individuals, the virtuous human would plausibly deem them both as bad individuals, given the virtuous human's commitment to reducing the pain and suffering of other organisms. After all, Lott writes that such a commitment would lead a virtuous human to perhaps "help the [elephant seal] species live differently" so as to reduce the pain and suffering of seals inflicted by other male seals (Lott 366-7). The Ebola virus and Ebola-like microbe would not be inflicting suffering and destruction upon members of their own kind, but it is nevertheless plausible that the pain and suffering inflicted upon other organisms would also lead the virtuous human to judge that the virus and microbe are bad, given a commitment to benevolence. It is reasonable to think Foot would say the same, as she grants that "there is a place" for an enquiry of what is a better state of affairs as long as it is asked from within the viewpoint of a benevolent human, "given, for example, that the end is to relieve suffering or to see that justice is done." (2001: 49). So, the virtuous human would judge that both the virus and the microbe are bad, and indeed, equally bad, as the two were said to cause the same measure of 


\section{An Ebola-like microbe and the limits of kind-based goodness}

pain and suffering. ${ }^{29}$ So, Aristotelians do not have the theoretical resources to support a claim that the Ebola-like microbe is worse than the actual Ebola virus. However, we plausibly judge that the microbe is worse because it destroys for its own sake, even though the virus causes the same amount of suffering. So, the microbe's goodness or badness does not hold in virtue of considerations from the virtuous human standpoint alone. Thus, this casts doubt on the claim that only the vantage point internal to a lifeform should be used to evaluate something's goodness.

Perhaps the virtuous human objects to the microbe even more than the virus, not only from the level of pain inflicted, but also from the level of species-teleology. The thought here is that given a benevolent commitment to reducing animal suffering, a virtuous human would deem that the microbe is worse because of its very directedness towards destruction. However, more will need to be said by neo-Aristotelians as to how benevolence, construed as a commitment to reducing or relieving actual suffering, is supposed to also entail a negative judgement upon something else's mere directedness towards destruction (and suffering). This is not a straightforward task, for if the suggestion is that benevolence would frown upon something else's directedness toward destruction because of its potential to bring about actual suffering, then the negative judgment is really in virtue of that expected suffering. But the microbe and virus are equal on that score. So, if instead the claim is that human benevolence also negatively evaluates mere directedness toward destruction, the neoAristotelian would need an argument for this.

In addition to doubts whether Lott's virtuous human standpoint can account for the plausible comparative judgement above, it is important to also realize that neo-Aristotelians have not actually offered an argument that one should not appeal to a view external to the lifeform. So, even apart from whether the virtuous standpoint can account for the comparative judgement above, the Aristotelian would fail to dismiss the counterexample argument simply by stating that it relies upon that external standpoint. Even though Foot in "Utilitarianism and the Virtues" had rejected utilitarianism because she found its arguments unconvincing, there are other accounts of goodness that are not kind-based. Thus, even if they have eliminated utilitarianism (and broader utilitarian accounts of goodness beyond moral goodness), Foot and Lott have not actually offered an argument for their contention that goodness is only kind-based, and consequently they have not shown that it is mistaken to appeal to a view external to the lifeform.

What defenders of the Aristotelian categoricals account can be interpreted to have demonstrated are two things. First, Foot has the theoretical resources to argue that for any member of a kind, if it is good, its goodness is partly in virtue of satisfying standards for its kind. For example, having sharp claws and engaging in cooperative hunting are required for the good wolf but not the good deer. Indeed, a deer would not be good that had sharp claws and hunted (cooperatively or not)..$^{30}$

Second, neo-Aristotelians have also demonstrated that the lifeform conception is necessary for understanding living things. To see anything as an organism, we must recognize "some of its happenings as vital processes and some of its parts as organs or members of that organism." (Lott 374) Further, in order to recognize what vital processes are occurring, one must appeal to the larger

\footnotetext{
${ }^{29}$ Even if for some reason the microbe and the virus were evaluated by the virtuous human to be tied, and that neither was bad (perhaps because they destroy members of other kinds rather than members of their own kind), it is intuitively plausible that the microbe is worse than the virus, but the appeal to the virtues cannot explain this. ${ }^{30}$ See also footnote 24 .
} 


\section{An Ebola-like microbe and the limits of kind-based goodness}

context represented by the lifeform conception. Thompson points out that the same biochemical process may be a different vital process in different lifeforms: mitosis is reproduction in an amoeba, while it is part of self-maintenance in a human (Thompson 273). In addition to providing a way to determine what particular vital process is occurring, the lifeform conception also determines the kind-based standards of goodness, as that conception (articulated by the categoricals) expresses how the teleological ends are achieved, articulating: "how nourishment was obtained, how development took place, what defences were available, and how reproduction was secured. From all this, norms were derived, requiring, for instance, a certain degree of swiftness in the deer, [...]." (Foot 2001: 334) This is a compelling argument that there are kind-based standards of goodness. However, it does not argue that they are the only sort of standards there are of goodness. Further argument would be needed.

So, the thesis that a good individual must satisfy standards for its kind, and the thesis that the lifeform conception is ineliminable in understanding organisms and determining kind-based standards, commits one only to the conclusion that an individual's goodness is partly in virtue of satisfying those lifeform-based standards. The two theses do not entail that an individual's goodness is solely in virtue of satisfying those standards. So, they do not preclude that the thing's goodness is also partly determined by some other fact, possibly a fact appealing to something beyond a lifeform conception.

Let us take stock of the terrain we have covered. I had explained that when confronted with my counterexample, the neo-Aristotelian might respond that it mistakenly relies on a vantage point that is external to the lifeform conception. The only sense in which a functioning microbe is bad is from a human's benevolent standpoint and thus not bad in any sense beyond a kind-based lifeform conception. However, I argued that this virtuous human standpoint cannot account for a plausible comparative judgement between a microbe and actual Ebola, and thus argued that the microbe's goodness or badness does not obtain solely in virtue of considerations internal to that standpoint. Even aside from this, I have also just pointed out that the neo-Aristotelian has not actually provided argument that only the vantage point internal to a lifeform should be used to evaluate something's goodness. Hence, the neo-Aristotelian owes us an argument that it is mistaken to appeal to a view external to the lifeform. In the absence of such an argument, my counterexample thus gives reason to reject the Aristotelian position that something's goodness holds solely in virtue of satisfying kindbased standards. While such a conclusion is nonetheless consistent with a thing's goodness being partly in virtue of satisfying those standards, the conclusion does imply that an account of what goodness is solely in virtue of would include appeal to a kind-independent standard. This can explain why a functioning Ebola-like microbe is not good, as it fails the kind-independent standard. As alluded to before, further theorizing would be needed to fill out exactly how something would satisfy such a standard, and I hope to do this in future work. ${ }^{31}$

${ }^{31}$ See Chan (2021). 


\section{$\underline{\text { Works Cited }}$}

Bigelow, J. and Pargetter, R. (1987). Functions. Journal of Philosophy 86(4): 181-196. Reprinted in Allen, Bekoff, \& Lauder (1998) and in Buller (1999).

Boorse, C. (1976). “Wright on functions.” Philosophical Review, 85(1): 70-86.

Chan, Berman (2021). "A Platonic Kind-Based Account of Goodness.” Philosophia 49 (4):1369-1389.

Foot, Philippa. "Utilitarianism and the Virtues." Mind 94.374 (1985): 196-209.

Foot, Philippa. Natural goodness. Oxford: Oxford University Press, 2001.

Foot, Philippa "Rationality and Goodness" in Modern Moral Philosophy ed. Anthony O'Hear. Cambridge: CUP, 2004.

Fitzpatrick. Teleology and the Norms of Nature. New York: Garland, 2000.

Fitzpatrick. "Robust Ethical Realism, Non-naturalism, and Normativity." Oxford Studies in Metaetbics 3. 2008. 159-205.

Geach, Peter T. "Good and evil." Analysis 17.2 (1956): 33-42.

Glackin, Shane Nicholas. "Dolphin natures, human virtues: MacIntyre and ethical naturalism." Studies in History and Philosophy of Science Part C: Studies in History and Philosophy of Biological and Biomedical Sciences 39.3 (2008): 292-297.

Hursthouse, Rosalind. On Virtue Ethics. OUP Oxford, 1999.

Korsgaard, Christine M. "Two distinctions in goodness." The philosophical review 92.2 (1983): 169-195.

Kosman, L. The activity of being: An essay on Aristotle's ontology. Harvard University Press, 2013.

Lennox, James G. (2017). An Aristotelian Philosophy of Biology: Form, Function and Development. Acta Philosophica 26 (1):33-52.

Lott, "Have Elephant Seals Refuted Aristotle" Journal of Moral Philosophy 9.3 (2012): 353-375.

MacDonald, Scott. "Egoistic Rationalism: Aquinas's Basis for Christian Morality." in Beaty, M. ed., Christian Theism and the Problems of Philosophy. University of Notre Dame Press (1990).

MacIntyre, Alasdair C. Dependent rational animals: Why human beings need the virtues. Vol. 20. Open Court Publishing, 1999.

McDowell, John. "Two Sorts of Naturalism." In Virtues and Reasons, Rosalind Hursthouse, Gavin Lawrence, and Warren Quinn eds. Oxford: Clarendon Press, 1995. 149-179.

Moosavi, Parisa (2019). From Biological Functions to Natural Goodness. Philosophers' Imprint 19 (51)

Murphy, Mark C. God and moral law: On the theistic explanation of morality. Oxford University Press, 2011.

Polilov, A. A. (2015). How small is the smallest? New record and remeasuring of Scydosella musawasensis Hall, 1999 (Coleoptera, Ptiliidae), the smallest known free-living insect. ZooKeys, (526), 61.

Thompson, M. "The Representation of Life", in Hursthouse, Rosalind, Gavin Lawrence, and Warren Quinn ed., Virtues and reasons: Philippa Foot and moral theory: essays in honour of Philippa Foot. Oxford: Clarendon Press, 1995. 247-296.

Wright, L. (1973). "Functions". Philosophical Review, 82: 139-168. 